\title{
Clinical Outcomes of Salivary Gland Tumor Surgery: A 10-year-chart View
}

\author{
Tejasvi Vemuru ${ }^{1}$, Sanjeev Mohanty ${ }^{2}$, Vinoth Manimaran ${ }^{3}$, Shiva Priya ${ }^{4}$
}

\begin{abstract}
Background: Salivary gland tumors constitute about $3 \%$ of all head and neck tumors. We present a series of 104 cases of various salivary gland pathologies and the various modalities of surgeries done between January 2007 and July 2017.

Materials and methods: Total 104 patients with salivary gland tumors were included in this study, of which 76 patients had parotid tumors and 28 were submandibular gland tumors. The presence or absence of coexisting salivary gland stones, involvement or noninvolvement of ducts were all considered. Preoperatively, patients underwent fine needle aspiration cytology (FNAC) and imaging studies along with routine blood investigations.

Results: All patients underwent surgery and subsequent histopathological examination (HPE). The preoperative FNAC and postoperative HPE were not correlating in $6.5 \%$ of parotid tumors and in $3.5 \%$ of submandibular gland tumor. Anomalies in the fasciovenous planes were seen in $3 \%$ of the patients, which caused intraoperative difficulties. Postoperatively, five patients had salivary leak and three patients had neuropraxia, which was managed conservatively and the patients recovered subsequently between 3 months and 6 months postoperatively.

Conclusion: Surgery for salivary gland tumors has its own threats due to the close proximity of nerve, vessels, and ducts. Postoperative complications like nerve palsy is seen more common in malignant tumors in both parotid and submandibular gland tumors. A proper methodical assessment and awareness of the various anatomical anomalies intraoperatively may give good surgical outcomes in surgeries of salivary gland tumors. In our study, various anomalies were encountered and dealt appropriately.

Keywords: Mucoepidermoid carcinoma, Parotid, Pleomorphic adenoma, Submandibular gland.

International Journal of Head and Neck Surgery (2021): 10.5005/jp-journals-10001-1414
\end{abstract}

\section{INTRODUCTION}

Salivary gland tumors constitute about $3 \%$ head and neck tumors. They present a diverse range of histological and clinical behaviors. The rarity of these tumors, combined with diverse histology, provides a challenge for the treating surgeon, as there is no specific recommendation or management protocols designed for such varied pathology of salivary gland tumors.

\section{Materials and Methods}

A retrospective chart review of 104 patients with various salivary gland pathologies were included in the study. The study was conducted in a university hospital from January 2007 to July 2017.

\section{Aims and Objectives}

- To analyze the various surgical outcomes of salivary gland tumors.

- To analyze the correlation between the preoperative fine needle aspiration cytology (FNAC) and postoperative histopathological examination (HPE).

- To analyze the surgery-related morbidity.

All patients underwent preoperative ultrasonogram (USG), FNAC, and CECT neck.

Total 5 patients (4.8\%) of 104 patients had facial nerve palsies; neurological assessment was done and findings recorded.

All patients underwent surgical excision of tumor under general anesthesia done by experienced head and neck surgeons.

\footnotetext{
${ }^{1-3}$ Department of ENT, Head and Neck Surgery, Sri Ramachandra Institute of Higher Education and Research, Chennai, Tamil Nadu, India

${ }^{4}$ Department of ENT, Head and Neck Surgery, Karpagam Faculty of Medical Sciences and Research, Coimbatore, Tamil Nadu, India

Corresponding Author: Tejasvi Vemuru, Department of ENT, Head and Neck Surgery, Sri Ramachandra Institute of Higher Education and Research, Chennai, Tamil Nadu, India, Phone: +91 9840755393, e-mail: tejasvivemuru@gmail.com

How to cite this article: Vemuru T, Mohanty S, Manimaran V, et al. Clinical Outcomes of Salivary Gland Tumor Surgery: A 10-year-chart View. Int J Head Neck Surg 2021;12(1):11-14.

Source of support: Nil

Conflict of interest: None
}

Postoperatively, wound healing and cranial nerve functions were assessed. Postoperative histopathology was documented and compared with preoperative FNAC findings.

\section{Results}

A total of 104 patients were included in the study. Of which 56 were females and 48 were males. The age group ranged from 19 to 64 years (mean 43.32 years).

The patients presented with complaints like swelling in the neck, increased salivation, meal time increase in the size of swelling,

(0) The Author(s). 2021 Open Access This article is distributed under the terms of the Creative Commons Attribution 4.0 International License (https:// creativecommons.org/licenses/by-nc/4.0/), which permits unrestricted use, distribution, and non-commercial reproduction in any medium, provided you give appropriate credit to the original author(s) and the source, provide a link to the Creative Commons license, and indicate if changes were made. The Creative Commons Public Domain Dedication waiver (http://creativecommons.org/publicdomain/zero/1.0/) applies to the data made available in this article, unless otherwise stated. 
pain, loss of weight and appetite, tooth pain, and deviation of angle of mouth.

\section{Parotid Gland Swelling (Table 1)}

Table 1: Symptoms of parotid gland swelling

\begin{tabular}{ll}
\hline Symptoms & No. of patients \\
\hline Swelling & 71 \\
Increased salivation & 54 \\
Meal time increase in swelling & 49 \\
Pain & 23 \\
Deviation in angle of mouth & 5 \\
Loss of weight and appetite & 7 \\
Restrictive mouth opening & 8 \\
\hline
\end{tabular}

\section{Submandibular Swelling (Table 2)}

Table 2: Symptoms of submandibular swelling

\begin{tabular}{ll}
\hline Symptoms & No. of patients \\
\hline Swelling & 28 \\
Increased salivation & 21 \\
Pain & 13 \\
Loss of weight and appetite & 9 \\
Tooth ache & 7 \\
Meal time increasing in swelling & 21 \\
\hline
\end{tabular}

Preoperative FNAC was done in all patients and findings are as follows:

Of the 76 parotid swellings, preoperative FNAC revealed 62 benign and 14 malignant.

\section{Benign Neoplasms (Table 3)}

Table 3: Parotid tumors (benign)_preoperative diagnosis

\begin{tabular}{lc}
\hline Pleomorphic adenoma & 43 \\
Warthin's tumor & 14 \\
Lymphangioma & 4 \\
Neurofibroma & 1 \\
\hline
\end{tabular}

\section{Malignant Tumors (Table 4)}

Table 4: Parotid tumors (malignant) - preoperative diagnosis

\begin{tabular}{ll}
\hline Carcinoma ex-pleomorphic & 9 \\
adenoma & \\
Adenoid cystic carcinoma & 2 \\
Acinic cell carcinoma & 1 \\
Mucoepidermoid carcinoma & 2 \\
\hline
\end{tabular}

Significant lymphadenopathy was seen in six cases.

One case of ectopic salivary gland tumor of the minor salivary glands in the hard palate was identified and one patient was diagnosed to have synchronous pleomorphic adenoma of parotid and submandibular gland.
Of the 28 submandibular swellings, 21 were diagnosed to be benign and 7 malignant by FNAC.

\section{Benign (Table 5)}

Table 5: Submandibular tumors (benign)—preoperative diagnosis

\begin{tabular}{lr}
\hline Pleomorphic adenoma & 20 \\
Hemangioma & 1 \\
\hline
\end{tabular}

\section{Malignant (Table 6)}

Table 6: Submandibular tumors (malignant)—diagnosis

\begin{tabular}{|c|c|c|c|}
\hline \multicolumn{2}{|c|}{ Adenoid cystic carcinoma } & \multicolumn{2}{|l|}{1} \\
\hline \multicolumn{2}{|c|}{ Mucoepidermoid carcinoma } & 1 & \\
\hline \multicolumn{2}{|c|}{$\begin{array}{l}\text { Carcinoma ex-pleomorphic } \\
\text { adenoma }\end{array}$} & 5 & \\
\hline \multicolumn{4}{|c|}{$\begin{array}{l}\text { Significant lymphadenopathy was seen in two cases. } \\
\text { Preoperative USG was done in all patients (Tables } 7 \text { and 8): }\end{array}$} \\
\hline Site & Presen & f calculus & No of calculus \\
\hline Parotid & 28 & & 48 \\
\hline Submandibular & 12 & & 16 \\
\hline
\end{tabular}

Table 8: Duct involvement in ultrasonogram

\begin{tabular}{lll}
\hline Site & Duct involved & Not involved \\
\hline Parotid & 19 & 57 \\
Submandibular & 13 & 15 \\
\hline
\end{tabular}

All patients underwent CECT.

Preoperative facial nerve palsy was seen in five patients with parotid selling for whom FNAC revealed carcinoma ex-pleomorphic adenoma (three patients) and adenoid cystic carcinoma (two patients).

All patients underwent excision of tumor under general anesthesia.

Superficial parotidectomy was done in 51 patients (49.03\%) and total parotidectomy done in 15 patients (14.4\%).

Modified Blair incision was made for surgical access.

Intraoperatively, the facial nerve was identified in all patients undergoing parotidectomy except one patient with mucoepidermoid carcinoma.

- Facial nerve trunk with all branches identified in 75 patients

- One patient-facial nerve trunk could not be identified

For submandibular gland tumors, horizontal skin crease incision was made.

In the surgery for submandibular gland tumors surgery, marginal mandibular nerve, hypoglossal and lingual nerve was identified in all patients except four patients with suspected malignancy lingual and hypoglossal nerve could not be identified. Postoperative histopathology:

Of the 76 parotid specimens, 57 were benign and 19 malignant. Postoperative histopathology in parotid tumors: 


\section{Benign (Table 9)}

Table 9: Postoperative histopathology_-parotid tumors (benign)

\begin{tabular}{lr}
\hline Pleomorphic adenoma & 39 \\
Warthin's tumor & 13 \\
Intraparotid cyst & 1 \\
Lymphangioma & 4 \\
Neurofibroma & 1 \\
\hline
\end{tabular}

\section{Malignant tumors (Table 10)}

Table 10: Postoperative histopathology_-parotid tumors (malignant)

\begin{tabular}{ll}
\hline Carcinoma ex-pleomorphic adenoma & 13 \\
Adenoid cystic carcinoma & 2 \\
Acinic cell carcinoma & 1 \\
Mucoepidermoid carcinoma & 2 \\
\hline
\end{tabular}

Four patients diagnosed with pleomorphic adenoma was found to be carcinoma ex-pleomorphic adenoma postoperatively.

One patient with pleomorphic adenoma was found to be having intraparotid cyst postoperatively.

Postoperative histopathology in submandibular gland tumors:

\section{Benign (Table 11)}

Table 11: Postoperative histopathology—submandibular tumor (benign)

\begin{tabular}{ll}
\hline Pleomorphic adenoma & 19 \\
Hemangioma & 1 \\
\hline
\end{tabular}

\section{Malignant (Table 12)}

Table 12: Postopeative_-submandibular tumors (malignant)

\begin{tabular}{ll}
\hline Adenoid cystic carcinoma & 1 \\
Mucoepidermoid carcinoma & 1 \\
$\begin{array}{l}\text { Carcinoma ex-pleomorphic } \\
\text { adenoma }\end{array}$ & 6 \\
\hline
\end{tabular}

One case of pleomorphic adenoma, which was diagnosed preoperatively, was found to be carcinoma ex-pleomorphic adenoma postoperatively on HPE.

\section{Preoperative and Postoperative Fine Needle} Aspiration Cytology (Table 13)

Table 13: Comparison of preoperative and postoperative diagnosis

\begin{tabular}{llll}
\hline & & FNAC & Postoperative HPE \\
\hline Parotid & Benign & 62 & 58 \\
& Malignant & 14 & 18 \\
Submandibular & Benign & 21 & 7 \\
& Malignant & 20 & 8 \\
\hline
\end{tabular}

Preoperative FNAC reported as pleomorphic adenoma had a different pathology on HPE postoperatively in five patients (6.5\%).

In submandibular gland tumors, the FNAC was not correlating with postoperative HPE in one patient for whom malignancy was missed

\section{Postoperative Complications}

\section{Wound Infection}

Wound infection was seen in the immediate postoperative period in four patients who underwent parotidectomy and four patients post-submandibular gland excision.

\section{Nerve Palsy}

Facial nerve palsy was seen in five patients preoperative parotid tumor excision. Postoperatively, nerve palsy was seen in eight patients:

Two patients-carcinoma ex-pleomorphic adenoma One patient-neurofibroma

All the three patients who had nerve palsy postoperative developed neuropraxia, which recovered within 6 months (HouseBrackmann-grade III to grade I).

Postoperative submandibular gland excision, there was transient paresis of marginal mandibular nerve and hypoglossal nerve. ${ }^{1}$

- Marginal mandibular nerve palsy-three patients (two patients-carcinoma ex-pleomorphic adenoma and one patient-adenoid cystic carcinoma)

- Hypoglossal nerve palsy_1 patient (diagnosis - adenoid cystic carcinoma)

\section{Salivary Fistula}

Occurred in three patients post-parotidectomy and two patients post-submandibular gland excision.

Adjuvant radiotherapy was given to 21 patients diagnosed with malignant tumors

- 15 parotid tumors

- 6 submandibular gland tumors

Neck dissection was done in six patients with parotid malignancies with clinically significant lymph nodes and two patients with submandibular malignant tumors.

\section{Discussion}

This study aims at focusing the histopathological correlations between the preoperative FNAC and postoperative histopathology, intraoperative complications, and involvement of nerve preoperatively and postoperatively.

Among the 104 patients in this study, preoperative and Postoperative histopathology was not correlating in five patients with parotid tumors and one with submandibular gland tumor. Thus, FNAC was reliable in $95.7 \%$ of patients in this study. Fernandes et al. ${ }^{2}$ in the study on the diagnosis of salivary gland tumors by FNAC have discussed that the diagnostic accuracy ranges from 80.4 to $98 \%$ and also state that it is an effective method as OP basis.

Dhanalakshmi et al. ${ }^{3}$ in their study about correlative study of FNAC and HPE of salivary lesions have concluded that accuracy of FNAC was $76.8 \%$ in benign neoplasms and $100 \%$ in malignant neoplasms. In this study, accuracy is found to be $78.4 \%$ in benign neoplasms and $100 \%$ in malignant neoplasms.

Wierzbika et al. ${ }^{4}$ in their study on facial nerve paralysis of parotid gland malignant tumor had observed that facial palsy was present in $30 \%$ of patients with parotid malignancies and it was clinical symptom in $60 \%$ of patients. In this study, facial palsy occurred in $6.5 \%$ of the patients and has been the clinical symptom in three patients (23\%) with carcinoma ex-pleomorphic adenoma and two patients (100\%) with adenoid cystic carcinoma.

In this study, one patient $(0.9 \%)$ was diagnosed with minor salivary gland of the hard palate, histopathology being mucoepidermoid carcinoma. Bharathi et al. ${ }^{5}$ reported a case on mucoepidermoid carcinoma of the hard palate, for which resection of tumor was done by partial maxillectomy. The same was done for the patient in this study with good postoperative outcomes. 
The postoperative complications encountered in parotid surgeries include wound infection (5.2\%), facial palsy (6.5\%), and fistula (3.9\%). Thahim et al. ${ }^{6}$ in their study about the postoperative outcomes of parotid surgeries on 20 patients have found that facial palsy (15\%), wound infection (15\%), sialocele (10\%). These results are comparable with this study.

Monica et al. ${ }^{7}$ in their study on surgical complications of submandibular gland excision have reported paralysis of marginal mandibular nerve in $6.8 \%$ of patients. In this study, nerve palsy was seen in $10.7 \%$. This may be attributed to the more number of malignant cases in this study.

Intraoperatively, one of the main anomalies seen in parotid surgeries include anomalies in the fasciovenous plane, which led to severe bleeding. Anomalies of retromandibular vein were encountered. While achieving hemostasis due to damage of anomalous position of retromandibular vein, a branch of facial nerve was stretched, resulting in transient palsy. The recovery period was 4 months. In a study on the retromandibular vein in relation to the facial nerve, Kopuz et al. ${ }^{8}$ have discussed the anomalies in 30 cadavers and have noted that the vein lies lateral to the nerve in one case. In this study, the vein lies lateral to the nerve in 4 out of 79 cases.

The incidence of malignancy was seen in $23.6 \%$ of parotid tumors and $28.5 \%$ in submandibular gland tumors. ${ }^{9}$

The rare cases that were seen in the sample were a case of neurofibroma of the parotid gland, which also had the anomaly of retromandibular vein being lateral to the nerve. Intraoperatively massive bleeding was encountered, which was controlled. Postoperatively, the patient had facial palsy that recovered in 3 months. ${ }^{10}$

Thus salivary gland tumors are a large entity, with varied histopathological correlations, intraoperative findings, and anomalies, few of which were discussed here.

\section{ConcLusion}

Salivary gland tumors are slow-growing tumors and have varied histological types. Incidence of parotid tumors is more when compared to submandibular salivary gland tumors. The accuracy of FNAC is $95 \%$ in diagnosing salivary gland neoplasms. Postoperative complications like nerve palsy is seen more commonly in malignant tumors in both parotid and submandibular gland tumors. A proper methodical assessment and awareness of the various anatomical anomalies intraoperatively may give good surgical outcomes in surgeries of salivary gland tumors.

\section{References}

1. Eneroth CM. Salivary gland tumors in the parotid gland, submandibular gland, and the palate region. Cancer 1971;27(6):1415-1418. DOI: 10.1002/1097-0142(197106)27:6<1415::aidcncr2820270622>3.0.co;2-x.

2. Fernandes GC, Pandit AA. Diagnosis of salivary gland tumors by FNAC. Young 2000. 50-87.

3. Dhanalakshmi M, Rao LL, Krishnaswamy, et al. Fine needle aspiration cytology and histopathology of salivary gland lesions: a correlative study in a rural teaching hospital. J Chin Clin Med 2009;4(12):674-680.

4. Wierzbicka M, Kopeć T, Szyfter W, et al. The presence of facial nerve weakness on diagnosis of a parotid gland malignant process. Eur Arch Otorhinolaryngol 2012;269(4):1177-1182. DOI: 10.1007/s00405011-1882-6.

5. Bharathi U, Mahesh MS, Lingaraju N, et al. Mucoepidermoid carcinoma of palate: a case report. IJSS Case Rep Rev 2014;1(7):3-5.

6. Thahim K, Hussain Udaipurwala I, Kaleem M. Clinical manifestations, treatment outcome and post-operative complications of parotid gland tumours--an experience of 20 cases. J Pak Med Assoc 2013;63(12):1472-1475.

7. Hernando M, Maria Echarri R, Taha M, et al. Surgical complications of submandibular gland excision. Acta Otorrinolaringol Esp 2012;63(1):42-46. DOI: 10.1016/j.otorri.2011.08.001.

8. Kopuz C, Ilgi S, Yavuz S, et al. Morphology of the retromandibular vein in relation to the facial nerve in the parotid gland. Acta Anat (Basel) 1995;152(1):66-68. DOI: 10.1159/000147685.

9. Eveson JW, Cawson RA. Salivary gland tumours. A review of 2410 cases with particular reference to histological types, site, age and sex distribution. J Pathol 1985;146(1):51-58. DOI: 10.1002/ path. 1711460106.

10. Maheshwari V, Khan R, Jain A, et al. Neurofibroma of parotid. BMJ Case Rep 2011;2011:bcr0520114172. DOI: 10.1136/bcr.05.2011.4172. 